\title{
Re-evaluating the vertical mass-flux profiles of aeolian sediment at the southern fringe of the Taklimakan Desert, China
}

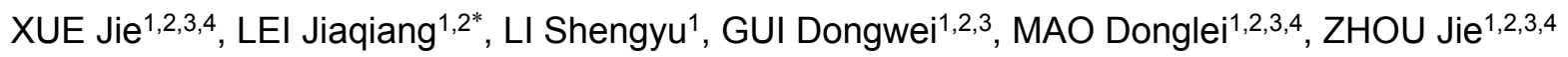 \\ ${ }^{1}$ State Key Laboratory of Desert and Oasis Ecology, Xinjiang Institute of Ecology and Geography, Chinese Academy of Sciences, \\ Urumqi 830011, China; \\ ${ }^{2}$ Cele National Station of Observation and Research for Desert-Grassland Ecosystem, Xinjiang Institute of Ecology and Geography, \\ Chinese Academy of Sciences, Cele 848300, China; \\ ${ }^{3}$ Key Laboratory of Biogeography and Bioresource in Arid Land, Xinjiang Institute of Ecology and Geography, Chinese Academy of \\ Sciences, Urumqi 830011, China; \\ ${ }^{4}$ University of Chinese Academy of Sciences, Beijing 100049, China
}

\begin{abstract}
Reliable estimation of the mass-flux profiles of aeolian sediment is essential for predicting sediment transport rates accurately and designing measures to cope with wind-erosion. Vertical mass-flux profiles from seventeen wind-erosion events were re-evaluated using five typical models based on observed data obtained from a smooth bare field at the southern fringe of the Taklimakan Desert, China. The results showed that the exponential-function model and the logarithmic-function model exhibited the poorest fit between observed and predicted mass-flux profiles. The power-function model and the modified power-function model improved the fit to field data to an equivalent extent, while the five-parameter combined-function model with a scale constant $(\sigma)$ of $0.00001 \mathrm{~m}$ (different from the $\sigma$ value proposed by Fryear, which represented the height above which $50 \%$ of the total mass flux occurred) was verified as the best for describing the vertical aeolian sediment mass-flux profiles using goodness of fit $\left(R^{2}\right)$ and the Akaike Information Criterion (AIC) values to evaluate model performance. According to relationships among model parameters, the modified power model played a prominent explanatory role in describing the vertical profiles of the observed data, whereas the exponential model played a coordinating role. In addition, it was found that the vertical profiles could not be extrapolated using the five selected models or easily estimated using an efficient model without field observations by a near-surface sampler at 0 to $0.05 \mathrm{~m}$.
\end{abstract}

Keywords: vertical profile; mass flux; aeolian sediment; wind erosion; Taklimakan Desert

Citation: XUE Jie, LEI Jiaqiang, LI Shengyu, GUI Dongwei, MAO Donglei, ZHOU Jie. 2015. Re-evaluating the vertical mass-flux profiles of aeolian sediment at the southern fringe of the Taklimakan Desert, China. Journal of Arid Land, 7(6): 765-777. doi: 10.1007/s40333-015-0134-9

Wind erosion is a natural process that generally occurs in semiarid and arid regions. Approximately one-third of global land area is influenced by wind erosion, and the area affected by wind erosion continues to expand (Lal, 1990; Sterk and Raats, 1996; Dong and Qian, 2007). Wind erosion occurs when the forces imposed by wind overcome the cohesive and gravitational forces of sediment particles on the land surface. It has a severe effect on agricultural and environmental conditions, including land degradation resulting from decreased soil fertility, destruction of crops by abrasion and burial in sand, decreased atmospheric visibility because of aeolian sediment transport during high wind events, and dust release by deposition (Pettke et al., 2000; Lal, 2001; Dong and Qian, 2007). In addition, wind-blown dust in the air can not only impact air quality, but can also cause asthma and other human health problems (Griffin et al., 2001). Therefore, academic interest

*Corresponding author: LEI Jiaqiang (E-mail: desert@ms.xjb.ac.cn) Received 2014-12-27; revised 2015-03-09; accepted 2015-07-01

(C) Xinjiang Institute of Ecology and Geography, Chinese Academy of Sciences, Science Press and Springer-Verlag Berlin Heidelberg 2015 
in this regard has already been widespread for several decades.

Understanding sediment movement by wind is the foundation of research into aeolian processes and of coping with wind-erosion problems. Creep, saltation, and suspension (Bagnold, 1941) are three modes of movement for aeolian sediment particles, the study of which is essential to a deeper understanding of the physical processes involved in aeolian sediment transport. For obtaining accurate estimates of sediment-transport rates for the three modes, particularly saltation which accounts for approximately 75\% of total horizontal mass transport (Bagnold, 1941; Chepil, 1945; Zheng, 2009), mathematical models of aeolian sediment transport have been developed since Bagnold (1937) first proposed a conceptual model of transport rate (e.g. Owen, 1940; Anderson and Hallet, 1986; Ungar and Haff, 1987; Anderson and Haff, 1988; Werner, 1990; Anderson et al., 1991; Sørensen, 1991; Kok and Renno, 2009; Shao, 2009). One common characteristic of these models is that total mass transport is the integral of the horizontal mass flux of sediment particles from the land surface to the height of the particle-bearing layer. This means that precise estimation of the vertical profiles of aeolian mass fluxes is crucial for accurate prediction of sediment transport rate, calibration and evaluation of different transport-rate models, scientific interpretation of particle-modified wind flows, verification of numerical models using trajectory equations (Butterfield, 1999), estimation of the vertical intensity of aeolian abrasion, and design of measures to construct protection against drifting sand (Chepil, 1945; Anderson and Hallet, 1986; Ni et al., 2002; Dong and Qian, 2007). Therefore, much work is needed to discover a realistic law for describing vertical mass-flux profiles and to obtain deeper knowledge of wind-erosion processes.

A considerable number of studies on sediment particle movement using different approaches, such as wind-tunnel tests (e.g. Williams, 1964; White, 1982; Butterfield, 1999; Dong and Qian, 2007), field observations (e.g. Fryrear and Saleh, 1993; Greeley et al., 1996; Dong et al., 2011), numerical simulations (e.g. Ungar and Haff, 1987; Werner, 1990; McEwan and Willetts, 1991; Sørensen, 1991; Shao, 2009), and the- oretical analyses (e.g. Owen, 1940; Anderson and Haff, 1988; Zheng et al., 2004; Shi and Huang, 2010), have characterized the vertical profiles of aeolian sediment mass flux. The results of all these studies indicated that the mass-flux along vertical profiles obeyed a particular function and decreased monotonically with heights. However, these studies proposed various function-fitting models which were largely determined by their respective experimental conditions and background. Existing models for describing vertical aeolian sediment mass-flux profiles can be summarized into four categories: exponential-function models, power-function models, logarithmic-function models, and combined-function models (Table 1). The models used to fit the vertical mass-flux profiles of aeolian sediment depend mainly on particle-size distribution and experimental measurement techniques. In addition, field surface conditions (Dong et al., 2011) and wind speed (Gillette et al., 1997; Ni et al., 2002; Du et al., 2014) are other reasons why different models have been developed. Because of the limitations of measurement techniques and the inadequacy of observation heights, agreement has not been reached on a physically realistic model to provide an optical fit to observed field data. Therefore, there is an increasing need to re-evaluate the reasonableness of fitted models and to develop a more appropriate model to predict vertical mass-flux profiles reliably.

The purpose of this study was to re-evaluate five representative models used to represent vertical aeolian sediment mass-flux profiles based on data collected by Big Spring Number Eight (BSNE) samplers at 0.05 to $2.00 \mathrm{~m}$ above a smooth bare field surface at the southern edge of the Taklimakan Desert, China, and to identify the best-fit model for describing the vertical profile by means of goodness of fit $\left(R^{2}\right)$ and the Akaike Information Criterion (AIC). This research also used field experimental data to obtain new calibration coefficients and to compare them with the original coefficients. Moreover, the physical implications of these coefficients for the models and the parameter relationships between models were interpreted. Finally, the reliability of extrapolation for five selected models at heights of 0 to $0.5 \mathrm{~cm}$ was verified based on collected data and using a near-surface sampler. 


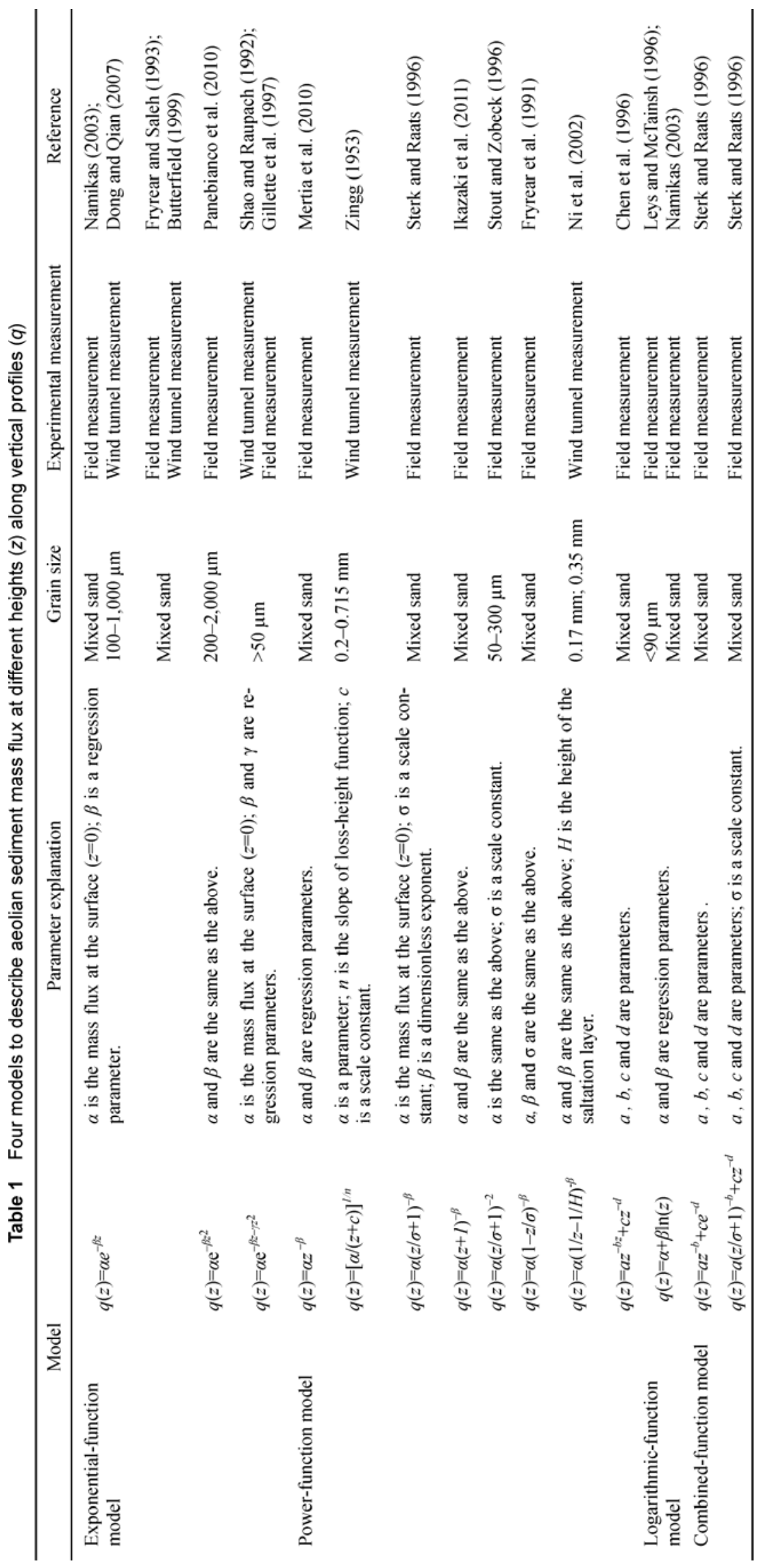




\section{Materials and methods}

\subsection{Study area}

The study area is situated in a smooth bare field at the southern fringe of the Taklimakan Desert, China ( $37^{\circ} 08^{\prime} 37^{\prime \prime} \mathrm{N}, 80^{\circ} 38^{\prime} 53^{\prime \prime} \mathrm{E}$; Fig. 1), which is $4.7 \mathrm{~km}$ from Cele National Station of Observation and Research for Desert-Grassland Ecosystem, Xinjiang Institute of Ecology and Geography, Chinese Academy of Sciences. It is an extremely arid land in a warm temperate zone. Extreme drought in the region makes local ecosystems among the most fragile in the world. The dominant landscape of the area is desert. The annual mean temperature is $11.9^{\circ} \mathrm{C}$, and the mean annual precipitation is $33.1 \mathrm{~mm}$. The annual mean wind velocity at a height of $2 \mathrm{~m}$ is $2.36 \mathrm{~m} / \mathrm{s}$, with wind erosion occurring mainly between March and October. The study area is located in the leeward zone of the Tarim Basin, which contains a wind-erosion zone $1,400 \mathrm{~km}$ in length. The southern fringe of the Taklimakan Desert is one of the areas most affected by wind-blown sand in China. Sand storms often occur there, and wind-erosion activities seriously restrict the economic and social development of Cele county. The sediment grains in the study area largely consisted of fine sand $(0.25-0.125 \mathrm{~mm}, 14.32 \%)$, very fine sand (0.125-0.063 mm, 60.43\%), and silt (0.063-0.002 mm, $25.24 \%$ ), with the remaining size categories accounting for only $0.01 \%$.

\subsection{Field observations}

Observations were conducted in a $50 \mathrm{~m} \times 50 \mathrm{~m}$ field surrounded by infinite sand sources and a non-erodible

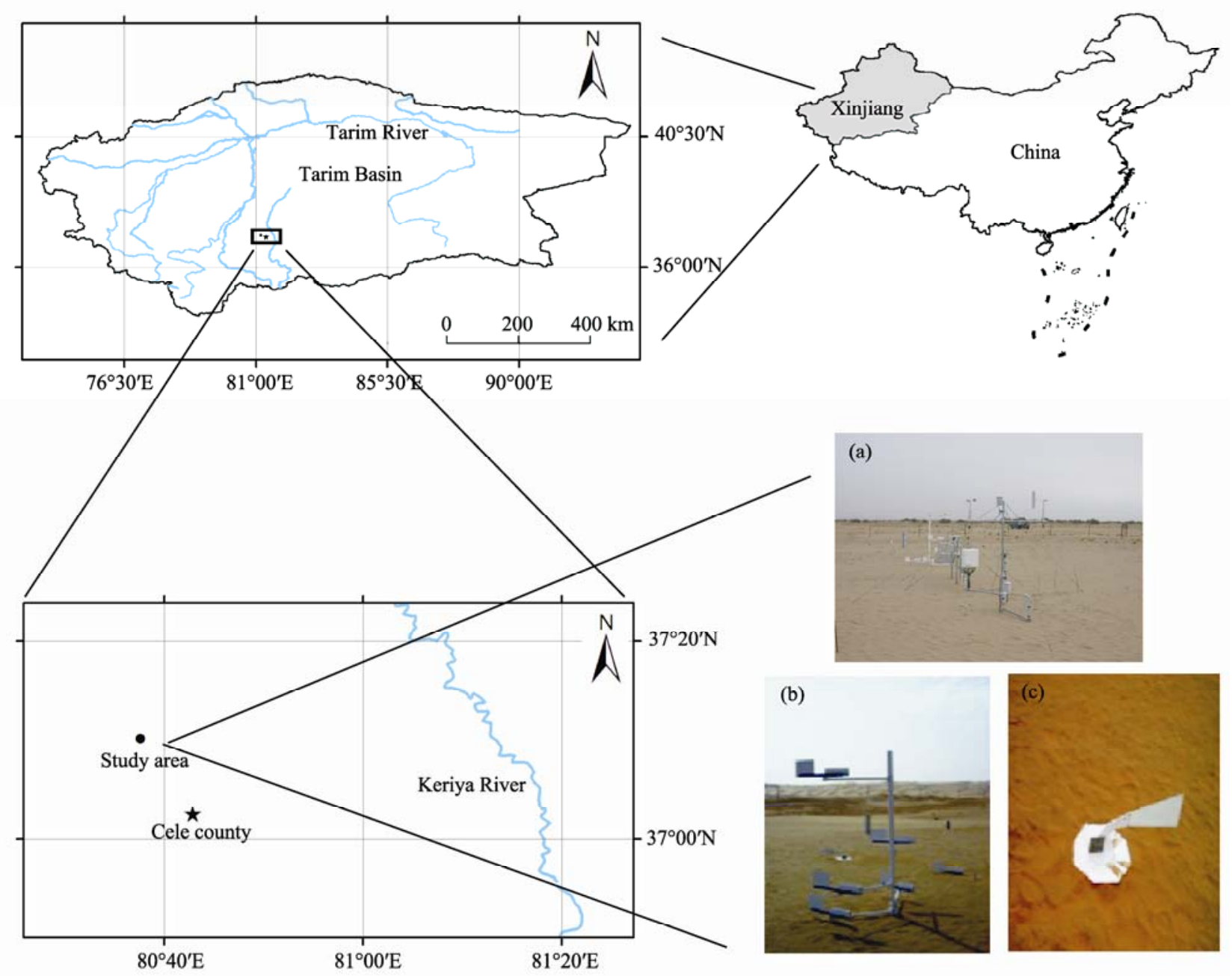

Fig. 1 Geographical location of the study area. (a), BSNE sampler; (b), near-surface sampler. 
boundary. Seventeen wind-erosion events were observed during 2010 and 2011. Wind-erosion activity is directly influenced by wind speed. Aeolian sediment transport occurs frequently during high wind events. Yang et al. (2012) found that the minimum mean threshold wind velocity of sand movement at a height of $2 \mathrm{~m}$ at the southern fringe of the Taklimakan Desert was $4.8 \mathrm{~m} / \mathrm{s}$. Therefore, wind-erosion events with mean wind speeds equal to or greater than $4.8 \mathrm{~m} / \mathrm{s}$ were considered in this research. Table 2 lists the duration, mean wind speed, and maximum gust speed at $2 \mathrm{~m}$ for the seventeen wind-erosion events. From statistical analysis of each event, the maximum gust speed at a height of $2 \mathrm{~m}$ was found to be quite high $(>10.28 \mathrm{~m} / \mathrm{s})$ and reached almost $20 \mathrm{~m} / \mathrm{s}$ in early June 2010 . Likewise, the mean wind speed at $2 \mathrm{~m}$ was also fairly large $(>5.20 \mathrm{~m} / \mathrm{s})$. Because $\mathrm{W}$ and $\mathrm{WNW}$ were the main prevailing wind directions causing wind erosion in the study area, the fetch effect was considered relatively constant.

Aeolian sediment was collected by the BSNE samplers (Fryrear, 1987; Fig. 1b), which are commonly used internationally and whose efficiency of collecting sand is more than $90 \%$ (Shao et al., 1993). The samplers were installed at six different heights $(5,10,20$, 50,100 , and $200 \mathrm{~cm}$ ) above the sand surface. Moreover, the near-surface samplers (Zobeck, 2003) trapped near-surface creep-saltation sediment at four different heights $(0.0,0.5,1.0$, and $2.0 \mathrm{~cm})$, making it possible to verify the reliability of extrapolation from models fitted at 0.05 to $2.00 \mathrm{~m}$ heights (Fig. 1c). Due to the smooth sediment surface, as well as the infinite supply of sand, spatial mass-flux variability was assumed to be spatially homogeneous. Therefore, the BSNE samplers and the near-surface samplers were placed at the center of the study area.

Table 2 Wind speeds and directions at 2-m height for seventeen wind erosion events at the southern fringe of the Taklimakan Desert

\begin{tabular}{|c|c|c|c|c|c|}
\hline No. & Date (dd/mm/уyyy) & Duration (min) & Mean wind speed $(\mathrm{m} / \mathrm{s})$ & Maximum wind speed $(\mathrm{m} / \mathrm{s})$ & Wind direction \\
\hline 1 & 09/05/2010 & 1,920 & 6.52 & 11.42 & WNW \\
\hline 2 & $13 / 05 / 2010$ & 900 & 6.64 & 13.66 & W \\
\hline 3 & $15 / 05 / 2010$ & 1,560 & 6.32 & 14.09 & WSW \\
\hline 4 & $24 / 05 / 2010$ & 2,820 & 6.35 & 14.85 & W \\
\hline 5 & 03/06/2010 & 1,260 & 7.29 & 19.80 & W \\
\hline 6 & $23 / 06 / 2010$ & 3,060 & 6.53 & 17.51 & WSW \\
\hline 7 & 08/07/2010 & 720 & 6.43 & 10.46 & SW \\
\hline 8 & $20 / 07 / 2010$ & 850 & 5.98 & 10.28 & NW \\
\hline 9 & $10 / 08 / 2010$ & 1,260 & 6.48 & 11.42 & $\mathrm{~W}$ \\
\hline 10 & $24 / 08 / 2010$ & 2,760 & 5.78 & 12.94 & NW \\
\hline 11 & $13 / 09 / 2010$ & 900 & 6.43 & 12.56 & WNW \\
\hline 12 & $05 / 10 / 2010$ & 120 & 7.52 & 13.43 & W \\
\hline 13 & $22 / 10 / 2010$ & 180 & 6.78 & 18.65 & SSW \\
\hline 14 & $26 / 06 / 2011$ & 1,820 & 5.62 & 16.37 & WSW \\
\hline 15 & $24 / 07 / 2011$ & 480 & 6.25 & 14.85 & WNW \\
\hline 16 & $11 / 09 / 2011$ & 300 & 5.93 & 15.99 & WNW \\
\hline 17 & 09/10/2011 & 780 & 6.32 & 11.80 & NW \\
\hline
\end{tabular}

The term "sediment mass flux" denotes the mass of sediment passing through a unit area perpendicular to the transect in a unit time. For quantifying vertical mass-flux profiles of aeolian sediment, the unit of sediment mass flux will be defined as $\mathrm{kg} /\left(\mathrm{m}^{2} \cdot \mathrm{min}\right)$. After the sampling, the sediment in each trap was collected and weighed, and the horizontal mass flux at each sampling height was calculated. The remaining calculations were performed to fit the models.

\subsection{Five typical models}

It is well known that the mass flux along vertical profiles of aeolian sediment decreases monotonically with heights. Previous researchers have proposed various 
models to fit this phenomenon. Large quantities of field and wind-tunnel data have demonstrated that the mass flux of aeolian sediment follows an exponential-decay function model with increasing height. This model can be expressed as:

$$
q(z)=\alpha e^{-\beta z} .
$$

Where $q(z)$ is the mass flux at height $z$ above the sediment surface, $\alpha$ is the mass flux at the surface $(z=0)$, and $\beta$ is a regression parameter that reveals the characteristic height of the mass-flux profile.

Butterfield (1999) maintained that the sediment mass flux can be expressed by a realistic law using a power-function model, which can be written as:

$$
q(z)=\alpha z^{-\beta} .
$$

Where $\alpha$ and $\beta$ are regression parameters. Sterk and Raat (1996) modified the power-function model as follows:

$$
q(z)=\alpha(\mathrm{z} / \sigma+1)^{-\beta} .
$$

Where $\alpha$ refers to the mass flux at the surface $(z=0)$, $\sigma$ is a length scale, and $\beta$ is a dimensionless exponent.

Furthermore, Leys and McTainsh (1996) and Namikas (2003) found that the field mass flux followed a logarithmic-function model with increasing heights along vertical profiles:

$$
q(z)=\alpha+\beta \ln (z) .
$$

Where $\alpha$ and $\beta$ are regression parameters.

Some researchers (e.g. Takeuchi, 1980; Fryrear, 1987; Ni et al., 2002) insisted that the mass flux of suspended sediment decreased with heights of the vertical profile as a power-function model, while the transport flux of saltating sediment decayed as an exponential-function model with increasing heights (e.g. Williams, 1964; Nalpanis, 1985; Dong et al., 2003). Therefore, the combined-function model was proposed by Sterk and Raat (1996):

$$
q(z)=a(z / \sigma+1)^{-b}+c e^{-d z} .
$$

Where $a, b, c, d$ are parameters and $\sigma$ is a scale constant. The first term on the right-hand side in the model was regarded as representing the mass flux in suspension, while the second term was considered to refer to the saltation flux and also included creep flux (Vories and Fryrear, 1991; Fryrear and Saleh, 1993).

\subsection{Evaluation of model performance}

\subsubsection{Goodness of fit $\left(R^{2}\right)$}

It is widely accepted that a measure of goodness of fit interprets how well a model fits a set of observed data. The goodness of fit is also called the coefficient of determination, which summarizes the deviation between observed values and the values estimated by a simulation model. The coefficient of determination can be expressed as:

$$
R^{2}=\frac{\sum_{i=1}^{n}\left(\bar{q}-q_{i, o b s}\right)^{2}-\sum_{i=1}^{n}\left(q_{i, o b s}-q_{i, e s t}\right)^{2}}{\sum_{i=1}^{n}\left(\bar{q}-q_{i, o b s}\right)^{2}} .
$$

Where $R$ denotes the correlation coefficient, $\bar{q}$ is the average of the observed data, $n$ is the number of samples, and $q_{i, o b s}$ and $q_{i, e s t}$ are the observed and estimated values, respectively. The value of $R^{2}$ ranges between 0 and 1 . The greater the $R^{2}$ value, the better the observed data have been fitted by the model. When the goodness of fit $\left(R^{2}\right)$ is equal to one, the model perfectly describes the data, and vice versa.

\subsubsection{Akaike Information Criterion (AIC)}

Akaike Information Criterion (AIC) was first proposed in 1974 by Akaike (Akaike, 1974). This method is extensively used to consider the deviation of fit and the number of parameters. The best of the five selected models was chosen by means of AIC (Mertia et al., 2010):

$$
A I C=n \ln \left[\sum_{i=1}^{n}\left(q_{i, o b s}-q_{i, e s t}\right)^{2}\right]+2 p .
$$

Where $p$ is the number of model parameters. The smallest AIC value among the estimated models identifies the best simulation performance and the most accurate description of the vertical aeolian sediment mass-flux profile.

\section{Results and discussion}

\subsection{Evaluation of model performance}

Aeolian sediment mass flux decreased monotonically with increasing heights above the near-surface for all observed data from the southern fringe of the Taklimakan Desert. For quantifying the variation of aeolian sediment mass flux with heights above the surface from 0.05 to $2.00 \mathrm{~m}$, the five typical models 
for describing vertical mass-flux profiles were run to fit the seventeen sets of wind-erosion data (Fig. 2). The exponential-function model (Model 1) and the logarithmic-function model (Model 4) were unable to match the measured mass fluxes, while the power-function model (Model 2) and the modified power-function model (Model 3) fitted the observed data equivalently well. However, the five-parameter combined-function model demonstrated the best fit to the field data. In other words, Model 5 ideally describes the mass-flux profiles because it provides a remarkable ability to fit the data.

To obtain a reasonable evaluation of model performance, Table 3 lists the goodness of fit $\left(R^{2}\right)$ and AIC for the five models which fitted the observed mass fluxes. According to the $R^{2}$ values of the models, the exponential-function and logarithmic-function models provide unsatisfactory fit compared with the other three models for the seventeen wind-erosion events. This indicated that the two models were unable to describe the vertical profile basing on the observed data, whereas the power-function and modified power-function models were superior to the exponential-function and logarithmic-function models because they achieved $R^{2}$ values greater than 0.98 in all but two simulations. However, the five-parameter combined-function model gave the closest fit to the measured fluxes because all the $R^{2}$ values were greater than 0.99 (approaching 1) for the measured data. The results of fitting the vertical mass-flux profiles with heights on the basis of AIC were similar to those for goodness of fit $\left(R^{2}\right)$. The mean AIC value for Model 5 was the smallest among the five selected models, and therefore the five-parameter combined-function model was considered to provide the best fit to represent the vertical aeolian sediment mass-flux profiles measured from 0.05 to $2.00 \mathrm{~m}$ above the sediment surface.

The above discussion indicates that the vertical mass-flux profiles for aeolian sediment can be well described by a combined-function model with four parameters and one constant. In fact, the simpler power-function and modified power-function models may be sufficient to fit the field data in these experiments. Yang et al. (2012) has described the mass fluxes of wind-blown sand using a simple power-function mod- el up to $2 \mathrm{~m}$ above the surface in the same study area. However, the modified power-function model is more plausible than the simple power-function model because the former can represent realistic significant results for the surface $(z=0)$ (Sterk and Raats, 1996). However, because of the good fitting performance of the modified power-function model, we prefer the five-parameter combined models to describe the vertical mass-flux profiles of aeolian sediment. Although the exponential-function model provides a poor fit to the measured mass fluxes, the decay law dominated by saltation particles tends to follow an exponential function from 0.05 to $0.20 \mathrm{~m}$ for the data from the seventeen wind-erosion events. Suspended particles are dominant at heights greater than $0.20 \mathrm{~m}$, and therefore the simple power function or the modified power function can replace the exponential law. These results were in agreement with the conclusions of Chen et al. (1996), who found that the flow layer from 14 to $15 \mathrm{~cm}$ represented a transition from saltation to suspension where the curves of mass flux against height converge in the Taklimakan Desert of China.

It is reasonable to consider the vertical profiles of the horizontal mass flux of drifting sediment as a combined function with heights. The mass fluxes calculated by a single-function model deviate more from the observed mass fluxes than other models, and the exponential-function and power-function models may greatly underestimate or overestimate mass fluxes. Combining these models makes it possible to describe the actual mass-flux profiles for the empirical data in this study. This is in agreement with previous results (Vories and Fryrear, 1991; Stout and Zobeck, 1996), indicating that the mass flux of saltating sediment decreases with heights according to an exponential law, while the transport flux of suspended sediment decays with increasing heights according to a power law.

\subsection{Relationships among model parameters}

Although all five selected models showed that the mass flux of aeolian sediment along vertical profiles was monotonically decreasing, the exponential-function and logarithmic-function models could not represent the vertical distribution law for the measured data. Therefore, the parameters of the power-function and 


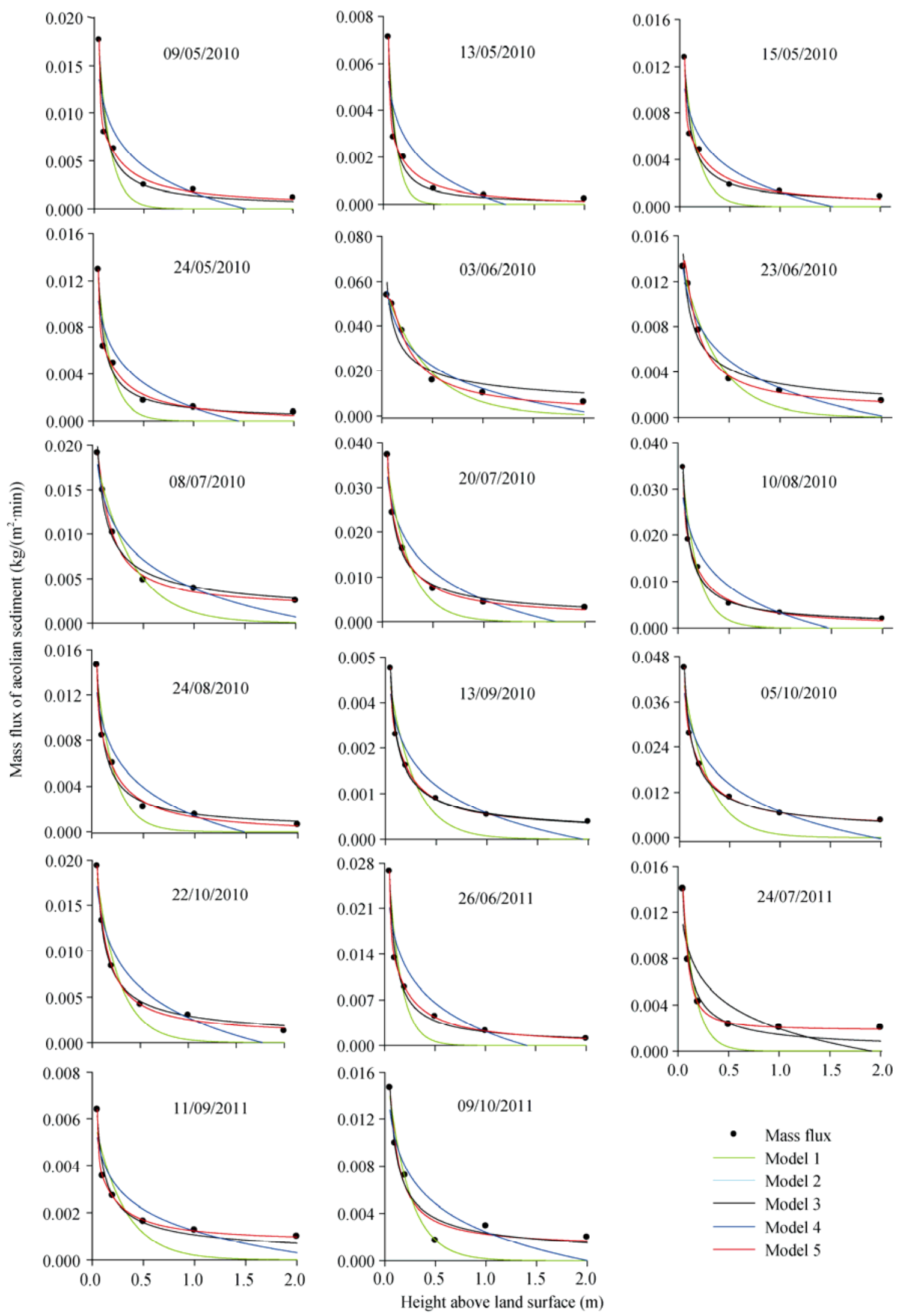

Fig. 2 Five selected models fitted to the vertical mass-flux profiles for seventeen wind-erosion events 
Table 3 Goodness of fit $\left(R^{2}\right)$ and AIC for the five models which fitted the observed mass fluxes

\begin{tabular}{|c|c|c|c|c|c|c|c|c|c|c|c|}
\hline \multirow{2}{*}{ No. } & \multirow{2}{*}{$\begin{array}{c}\text { Date } \\
\text { (dd/mm/yyyy) }\end{array}$} & \multicolumn{2}{|c|}{ Model 1} & \multicolumn{2}{|c|}{ Model 2} & \multicolumn{2}{|c|}{ Model 3} & \multicolumn{2}{|c|}{ Model 4} & \multicolumn{2}{|c|}{ Model 5} \\
\hline & & $R^{2}$ & AIC & $R^{2}$ & $\mathrm{AIC}$ & $R^{2}$ & $\mathrm{AIC}$ & $R^{2}$ & AIC & $R^{2}$ & AIC \\
\hline 1 & $09 / 05 / 2010$ & 0.763 & 17.985 & 0.982 & 2.339 & 0.982 & 2.387 & 0.809 & 27.970 & 0.994 & -4.263 \\
\hline 2 & $13 / 05 / 2010$ & 0.764 & 20.473 & 0.989 & 1.976 & 0.990 & 2.075 & 0.772 & 41.891 & 0.996 & -5.199 \\
\hline 3 & $15 / 05 / 2010$ & 0.759 & 24.210 & 0.985 & 6.174 & 0.985 & 6.165 & 0.835 & 65.783 & 0.992 & 3.940 \\
\hline 4 & $24 / 05 / 2010$ & 0.775 & 14.873 & 0.988 & -5.362 & 0.988 & -5.304 & 0.843 & 16.726 & 0.991 & -4.553 \\
\hline 5 & $03 / 06 / 2010$ & 0.874 & 14.505 & 0.961 & 14.406 & 0.961 & 14.390 & 0.960 & 12.312 & 0.994 & 12.712 \\
\hline 6 & $23 / 06 / 2010$ & 0.838 & -0.293 & 0.979 & -6.248 & 0.979 & -6.249 & 0.953 & 4.596 & 0.995 & -19.124 \\
\hline 7 & 08/07/2010 & 0.804 & -3.807 & 0.988 & -19.607 & 0.988 & -19.625 & 0.947 & 4.304 & 0.999 & -32.061 \\
\hline 8 & $20 / 07 / 2010$ & 0.798 & 6.562 & 0.995 & -17.466 & 0.995 & -17.117 & 0.918 & 6.199 & 0.999 & -26.970 \\
\hline 9 & $10 / 08 / 2010$ & 0.805 & 4.864 & 0.996 & -22.066 & 0.996 & -22.086 & 0.872 & 6.179 & 0.996 & -19.120 \\
\hline 10 & $24 / 08 / 2010$ & 0.865 & 1.329 & 0.986 & -15.204 & 0.986 & -15.258 & 0.896 & 5.180 & 0.995 & -19.493 \\
\hline 11 & $13 / 09 / 2010$ & 0.834 & -3.525 & 0.991 & -31.076 & 0.991 & -31.104 & 0.862 & 4.583 & 0.997 & -29.269 \\
\hline 12 & $05 / 10 / 2010$ & 0.803 & -24.582 & 0.998 & -55.045 & 0.998 & -54.946 & 0.904 & 4.235 & 0.999 & -55.232 \\
\hline 13 & $22 / 10 / 2010$ & 0.885 & 3.815 & 0.983 & -11.943 & 0.983 & -12.088 & 0.982 & 35.997 & 0.998 & -22.842 \\
\hline 14 & $26 / 06 / 2011$ & 0.868 & 14.740 & 0.991 & -8.705 & 0.991 & -8.720 & 0.914 & 160.64 & 0.998 & -12.911 \\
\hline 15 & $24 / 07 / 2011$ & 0.793 & 10.437 & 0.990 & -11.923 & 0.990 & -11.768 & 0.786 & 70.575 & 0.999 & -26.033 \\
\hline 16 & $11 / 09 / 2011$ & 0.717 & 8.483 & 0.985 & -5.569 & 0.981 & -5.564 & 0.669 & 53.176 & 0.999 & -23.148 \\
\hline 17 & 09/10/2011 & 0.772 & -18.799 & 0.989 & -44.473 & 0.989 & -44.390 & 0.865 & 4.609 & 0.996 & -42.023 \\
\hline
\end{tabular}

modified power-function models as well as the combined-function model are mainly discussed here. According to the parameters of the two power indices for the power-function and modified power-function models, the $\beta$ values of the two models were identical, a result which is inconsistent with those of previous researchers. For example, Stout and Zobeck (1996) maintained that the power index $(\beta)$ of the modified power-function model could be considered as a constant equal to 2 rather than a variable. It is undeniable that the power index $\beta$ was more reasonable as a decay coefficient for the experimental data in this study area because its value actually referred to the regression coefficient, i.e. the slope of a linear relationship. The $\sigma$ value of the modified power-function model was a length scale to describe the height of the vertical profile for the field data. The optimal $\sigma$ value was fitted as $0.00001 \mathrm{~m}$ in the model. When $\sigma$ was greater than $0.00001 \mathrm{~m}$, the goodness of fit $\left(R^{2}\right)$ became less. On the contrary, if $\sigma$ was less than $0.00001 \mathrm{~m}$, the $R^{2}$ value no longer varied. This conclusion was different from that proposed by Fryrear et al. (1991), who indicated that $\sigma$ was the height below which $50 \%$ of the total mass occurred. In fact, the power-function model was equivalent to the modified power-function model.
When the height $z$ was assumed to be approximately $z+\sigma(\sigma=0.00001 \mathrm{~m})$, the parameter $\alpha$ of the powerfunction model was comparable to $\alpha \sigma^{\beta}$ of the modified power-function model based on the same $\beta$. From a mathematical perspective, the modified power curve was a curve which was translated as $\sigma$ units by the power curve along the horizontal axis (height direction).

Many previous researchers (e.g. Fryrear et al., 1991; Sterk and Raats, 1996; Stout and Zobeck, 1996) indicated that the modified power-function model was capable to describe the realistic characteristics of the vertical profile for near-surface mass fluxes. In particular, $\alpha$ refers to the mass flux at $z=0$. When the power curve approaches the surface $(z=0)$, the mass flux loses its real-world significance because it tends towards infinity. Therefore, the modified power-law model becomes a plausibly reasonable reproduction of the real vertical profile. However, whether or not the extrapolation for heights less than $0.05 \mathrm{~m}$ was reliable, it remains necessary to verify near-surface profiles against measured data.

As described in the previous section, the combined model provided the best fit to the vertical aeolian mass-flux profile of the observed data in the study 
area according to the goodness of fit $\left(R^{2}\right)$ and AIC values used to evaluate model performance. In fact, the combined model was a compromise solution which coupled the modified power-function and exponential-function models. The value of $\sigma$ was still set to $0.00001 \mathrm{~m}$, while the remaining four parameters were the coefficients of variation. The two parameters $(\alpha$ and $\beta$ ) of the modified power-function model, which corresponded to the two parameters ( $a$ and $b$ ) of the modified power-function term in the combinedfunction model, had excellent positive linear correlations $\left(R^{2}>0.87\right)$. The parameter $(\alpha)$ of the exponential-function model, which corresponded to the parameter $(c)$ of the exponential-function term within the combined model, also showed exceptionally good correlation $\left(R^{2}=0.80\right)$, but the index parameters $(\beta$ and $d)$ of the two models performed irregularly at matching the observed data (Fig. 3). This implies that the modified power model played a prominent role in describing the vertical profile of the data, while the exponential model played a complementary role. This
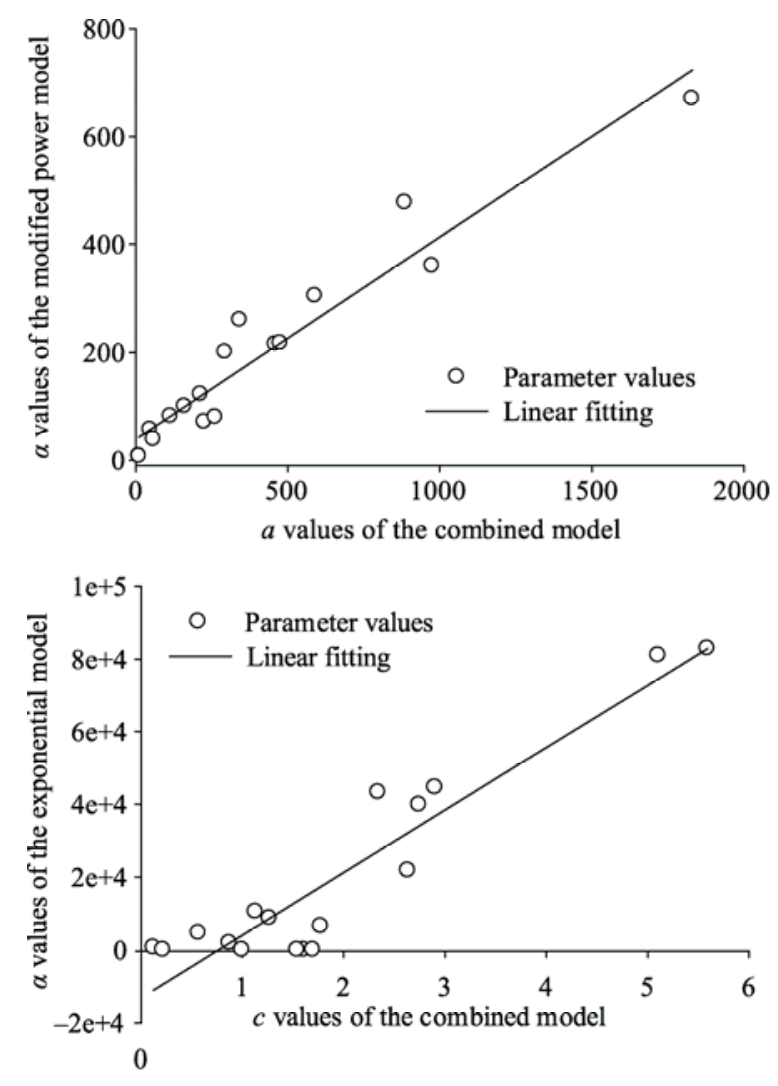

conclusion was roughly identical to that expressed by Sterk and Raats (1996).

\subsection{Reliability of extrapolation}

The vertical aeolian mass-flux profile should be described by a law covering the entire height from the surface $(z=0)$ to a meaningful height. Previous sections have mainly discussed the mass flux at heights from $0.05 \mathrm{~m}$ to $2.00 \mathrm{~m}$, while the mass flux below $0.05 \mathrm{~m}$ was generally estimated by extrapolation according to the effective model (Sterk and Raats, 1996). Actually, this arbitrary behavior was inadvisable. Figure 4 (all other cases were similar and therefore are not shown) illustrates the profiles below $0.05 \mathrm{~m}$ for the three cases during the observation periods as collected by near-surface samplers. Unfortunately, the vertical mass-flux did not decrease monotonically with increasing heights from 0 to $0.05 \mathrm{~m}$ for the observed data at the measurement site. All the curves, which fluctuated along the horizontal axis, resembled electrocardiogram traces. One peak value could be caused
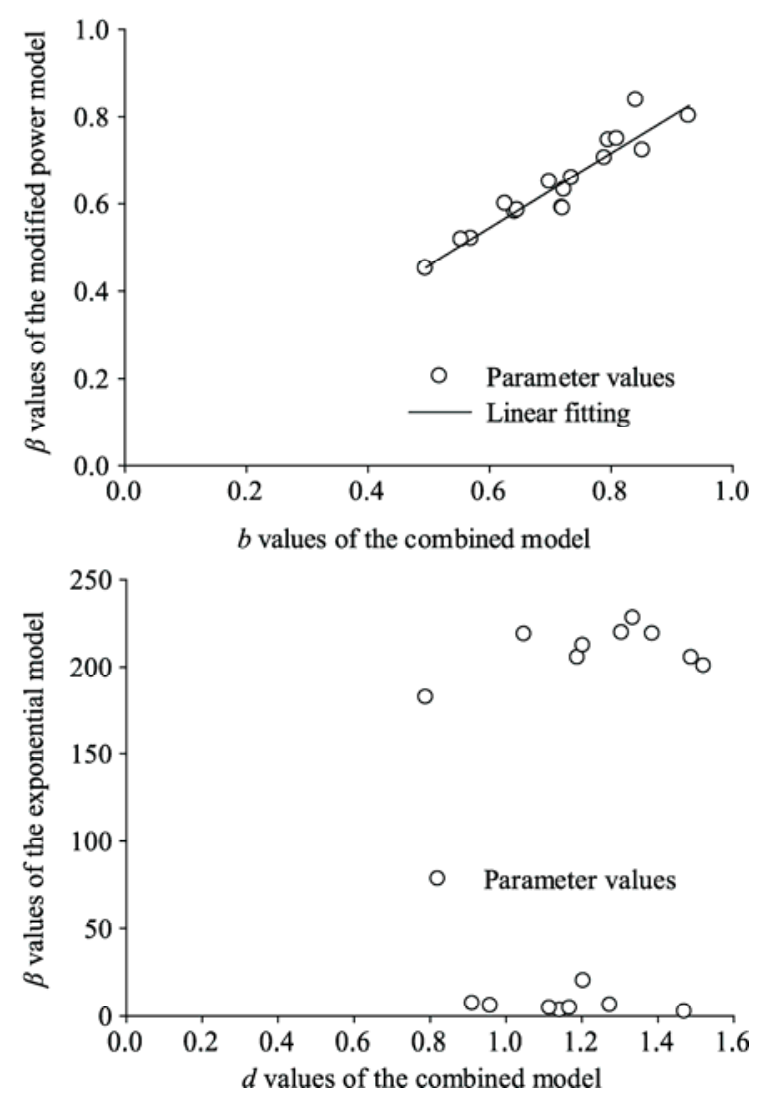

Fig. 3 Relationships among the Model $(1,3,5)$ parameters 

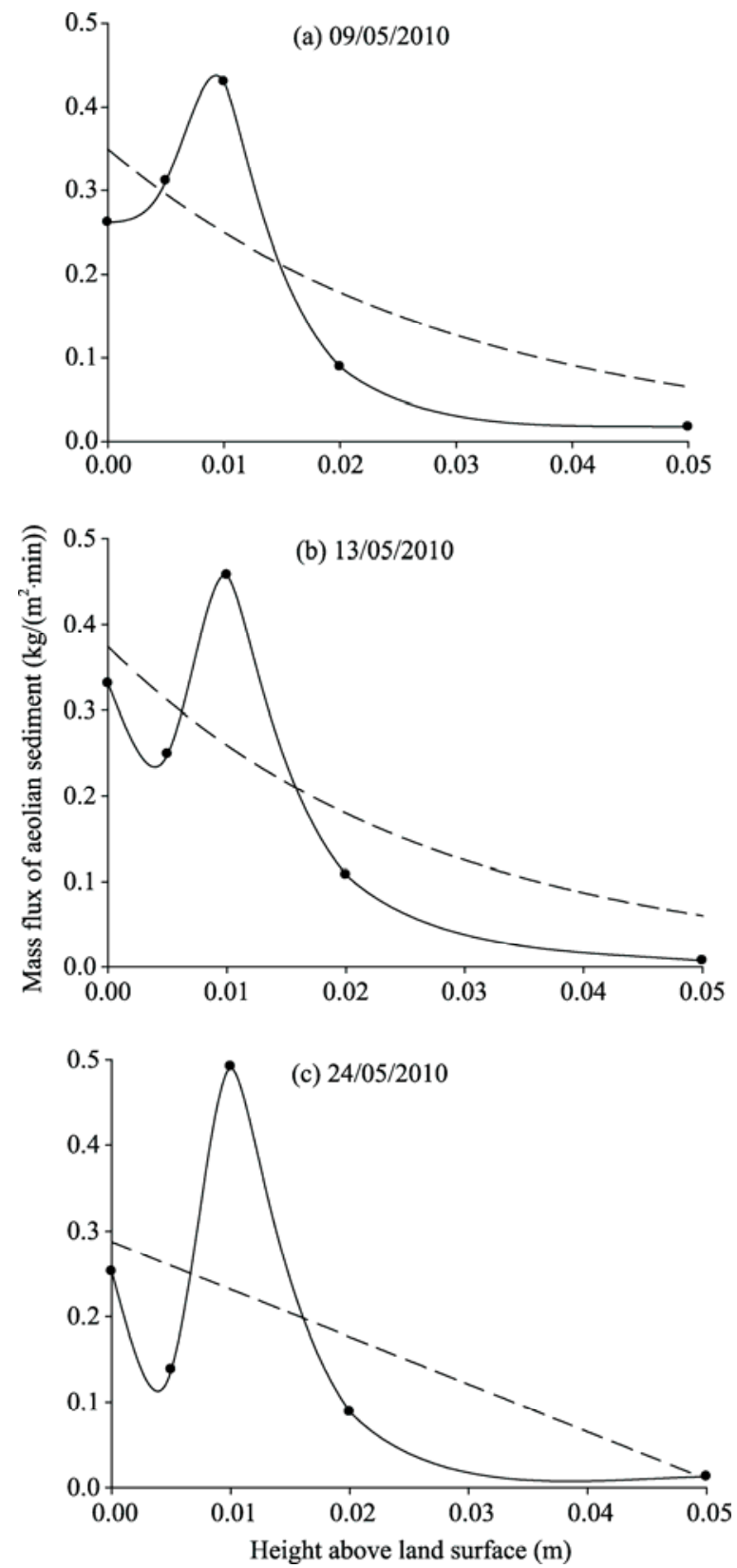

Fig. 4 Vertical profiles for three near-surface events from 0 to $0.05 \mathrm{~m}$ in Model 1

by the impact of particles on the surface (Anderson and Hallet, 1986). Therefore, the five models discussed in the previous sections could describe the vertical profiles only between 0.05 and $2.00 \mathrm{~m}$. The profiles below $0.05 \mathrm{~m}$ and above $2.00 \mathrm{~m}$ should be recalibrated through wind-tunnel and field experiments so that the model can accurately describe the vertical mass-flux characteristics of aeolian sediment. Reliability of the model was thus improved and inaccurate extrapolation from the selected model was avoided. This situation poses a challenge for measuring devices and presents an urgent scientific puzzle for solution.

\section{Conclusions}

In this research, five typical models (exponential-function, power-function, logarithmic-function, modified power-function, and combined-function models) proposed by previous researchers were selected to describe vertical aeolian mass-flux profiles. These models were re-evaluated on the basis of data collected from a smooth bare field at the southern edge of the Taklimakan Desert in China. By comparing the models' performance in fitting observed field data collected from six sampling heights by BSNE at 0.05 to $2.00 \mathrm{~m}$ above the sand surface, we determined that the resulting exponential-function and logarithmic-function models showed very poor fit between observed and predicted mass-flux profiles. The power-function and modified power-function models were equivalently effective in describing the vertical mass-flux profiles of the field data. However, the five-parameter combined model was the best at representing vertical aeolian sediment mass-flux profiles according to the goodness of fit $\left(R^{2}\right)$ and AIC values used to evaluate model performance. In the combined model, the scale constant $(\sigma)$ was $0.00001 \mathrm{~m}$, which was different from that proposed by Fryear, representing the height below which $50 \%$ of the total mass flux occurred. The two parameters $(\alpha$ and $\beta$ ) of the modified power-function model, which corresponded to the two parameters ( $a$ and $b$ ) of the modified power-function term in the combined-function model, exhibited excellent positive linear correlations $\left(R^{2}>0.87\right)$. The parameter $(\alpha)$ of the exponential-function model, which corresponded to the parameter $(c)$ of the exponential-function term within the combined model, also showed exceptionally good correlation $\left(R^{2}=0.80\right)$, while the index parameters ( $\beta$ and $d$ ) of the two models performed irregularly at fitting the observed data. These results indicate that the combined model was a compromise solution obtained by coupling the modified power-law model and the exponential-function model.

It was found that the vertical profiles could not be 
extrapolated using the five selected models and were estimated with difficulty using an efficient model without field observations by near-surface samplers at 0 to $0.05 \mathrm{~m}$.

For heights greater than $2.00 \mathrm{~m}$, due to the presence of many constraints, the reliability of extrapolation from the selected models was not verified. Because the performances of models are often influenced by numerous environmental factors, greater deviations will continue to exist between measured values and those estimated by model extrapolation. Therefore, testing and verifying the reliability of extrapolation from these mass-flux models using field measurements will be urgently needed in the future.

\section{Acknowledgements}

This study was financially supported by the Special Scientific Research Fund of Meteorological Public Welfare Profession of China (GYHY201106025) and the National Natural Science Foundation of China (41471031).

\section{References}

Akaike H. 1974. A new look at the statistical model identification. IEEE Transactions on Automatic Control, 19(6): 716-723.

Anderson R S, Hallet B. 1986. Sediment transport by wind: Toward a general model. Geological Society of America Bulletin, 97(5): 523-535.

Anderson R S, Haff P K. 1988. Simulation of eolian saltation. Science, 241(4857): 820-823.

Anderson R S, Sørensen M, Willetts B B. 1991. A review of recent progress in our understanding of Aeolian sediment transport. In: Barndorff-Nielsen O E, Willetts B B. Aeolian Grain Transport: Mechanics. Acta Mechanica Supplementum. Vienna: Springer, 1: 1-19.

Bagnold R A. 1937. The transport of sand by wind. The Geographical Journal, 89(5): 409-438.

Bagnold R A. 1941. The Physics of Blown Sand and Desert Dunes. New York: William Morrow \& Company, 12-36.

Butterfield G R. 1999. Near-bed mass flux profiles in Aeolian sand transport: high-resolution measurements in a wind tunnel. Earth Surface Processes and Landforms, 24(5): 393-412.

Chen W N, Yang Z T, Zhang J S, et al. 1996. Vertical distribution of wind-blown sand flux in the surface layer, Taklamakan Desert, Central Asia. Physical Geography, 17(3): 193-218.

Chepil W S. 1945. Dynamics of wind erosion: I. Nature of movement of soil by wind. Soil Science, 60(4): 305-320.

Dong Z B, Liu X P, Wang H T, et al. 2003. The flux profile of a blowing sand cloud: a wind tunnel investigation. Geomorphology, 49(3-4): 219-230.

Dong Z B, Qian G Q. 2007. Characterizing the height profile of the flux of wind-eroded sediment. Environmental Geology, 51(5): 835-845.
Dong Z B, Lu J F, Man D Q, et al. 2011. Equations for the near-surface mass flux density profile of wind-blown sediments. Earth Surface Processes and Landforms, 36(10): 1292-1299.

Du H Q, Xue X, Wang T. 2014. Estimation of the quantity of aeolian saltation sediments blown into the Yellow River from the Ulanbuh Desert, China. Journal of Arid Land, 6(2): 205-218.

Fryrear D W. 1987. Aerosol measurements from 31 dust storms. In: Ariman T, Veziroglu T N. Particulate and Multiphase Flows: Contamination Analysis and Control. New York: Hemisphere, 407-415.

Fryrear D W, Stout J E, Hagen L J, et al. 1991. Wind erosion: field measurement and analysis. Transactions of the American Society of Agricultural and Biological Engineers, 34(1): 155-160.

Fryrear D W, Saleh A. 1993. Field wind erosion: vertical distribution. Soil Science, 155(4): 294-300.

Gillette D A, Fryrear D W, Xiao J B, et al. 1997. Large-scale variability of wind erosion mass flux rates at Owens Lake, 1. Vertical profiles of horizontal mass fluxes of wind-eroded particles with diameter greater than $50 \mu \mathrm{m}$. Journal of Geophysical Research, 102(22): 25977-25987.

Greeley R, Blumberg D G, Williams S H. 1996. Field measurements of the flux and speed of wind-blown sand. Sedimentology, 43(1): 41-52.

Griffin D W, Kellogg C A, Shinn E A. 2001. Dust in the wind: Long range transport of dust in the atmosphere and its implications for global public and ecosystem health. Global Change and Human Health, 2(1): 20-33.

Ikazaki K, Shinjo H, Tanaka U, et al. 2011. Field-scale Aeolian sediment transport in the Sahel, West Africa. Soil Science Society of America Journal, 75(5): 1885-1897.

Kok J F, Renno N O. 2009. A comprehensive numerical model of steady state saltation (COMSALT). Journal of Geophysical Research, 114(D17), doi: 10.1029/2009JD011702.

Lal R. 1990. Soil Erosion in the Tropics: Principles and Management. New York: McGraw-Hill.

Lal R. 2001. Soil degradation by erosion. Land Degradation \& Development, 12(6): 519-539.

Leys J F, McTainsh G H. 1996. Sediment fluxes and particle grain-size characteristics of wind-eroded sediments in southeastern Australia. Earth Surface Processes and Landforms, 21(7): 661-671.

McEwan I K, Willetts B B. 1991. Numerical model of the saltation cloud In: Barndorff-Nielsen O E, Willetts B B. Aeolian Grain Transport: Mechanics. Acta Mechanica Supplementum. Vienna: Springer, 1: 53-66.

Mertia R S, Santra P, Kandpal B K, et al. 2010. Mass-height profile and total mass transport of wind eroded Aeolian sediments from rangelands of the Indian Thar Desert. Aeolian Research, 2(2-3): 135-142.

Nalpanis P. 1985. Saltating and suspended particles over flat and sloping surfaces: II. Experiments and numerical simulations. In: Barndorff-Nielsen O E, Møller J T, Rasmussen K R, et al. Proceedings of International Workshop on the Physics of Blown Sand. Denmark: Aarhus University, 37-66.

Namikas S L. 2003. Field measurement and numerical modelling of aeolian mass flux distributions on a sandy beach. Sedimentology, 50(2): 303-326. 
Ni J R, Li Z S, Mendoza C. 2002. Vertical profiles of Aeolian sand mass flux. Geomorphology, 49(3-4): 205-218.

Owen P R. 1964. The saltation of uniform sand in air. Journal of Fluid Mechanics, 20(2): 225-242.

Panebianco J E, Buschiazzo D E, Zobeck T M. 2010. Comparison of different mass transport calculation methods for wind erosion quantification purposes. Earth Surface Processes and Landforms, 35(13): 1548-1555.

Pettke T, Halliday A N, Hall C M, et al. 2000. Dust production and deposition in Asia and the north Pacific Ocean over the past $12 \mathrm{Myr}$. Earth and Planetary Science Letters, 178(3-4): 397-413.

Shao Y, Mctainsh G H, Leys J F, et al. 1993. Efficiencies of sediment samplers for wind erosion measurement. Australian Journal of Soil Research, 31(4): 519-532.

Shao Y P, Raupach M R. 1992. The overshoot and equilibration of saltation. Journal of Geophysical Research, 97(D18): 20559-20564.

Shao Y P. 2009. Physics and Modelling of Wind Erosion ( $2^{\text {nd }}$ ed.). Boston: Kluwer Academic Publishers.

Shi F, Huang N. 2010. Computational simulations of blown sand fluxes over the surfaces of complex microtopography. Environmental Modelling and Software, 25(3): 362-367.

Sørensen M. 1991. An analytic model of wind-blown sand transport. In: Barndorff-Nielsen O E, Willetts B B. Aeolian Grain Transport: Mechanics. Acta Mechanica Supplementum. Vienna: Springer, 1: 67-82.

Sterk G, Raats P A C. 1996. Comparison of models describing the vertical distribution of wind-eroded sediment. Soil Science Society of America Journal, 60(6): 1914-1919.

Stout J E, Zobeck T M. 1996. The Wolfforth field experiment: a wind erosion study. Soil Science, 161(9): 616-632.

Takeuchi M. 1980. Vertical profile and horizontal increase of drift-snow transport. Journal of Glaciology, 26(94): 481-498.

Ungar J E, Haff P K. 1987. Steady state saltation in air. Sedimentology, 34(2): 289-299.

Vories E D, Fryrear D W. 1991. Vertical distribution of wind-eroded soil over a smooth, bare field. Transactions of the Asae, 34:1763-1768.

Werner B T. 1990. A steady-state model of wind-blown sand transport. The Journal of Geology, 98(1): 1-17.

White B R. 1982. Two-phase measurements of saltating turbulent boundary layer flow. International Journal of Multiphase Flow, 8(5): 459-473.

Williams G. 1964. Some aspects of the Aeolian saltation load. Sedimentology, 3(4): 257-287.

Yang X H, He Q, Mamtimin A, et al. 2012. A field experiment on dust emission by wind erosion in the Taklimakan Desert. Acta Meteorologica Sinica, 26(2): 241-249.

Zheng X J, He L H, Wu J J. 2004. Vertical profiles of mass flux for windblown sand movement at steady state. Journal of Geophysical Research, 109(B1), doi: 10.1029/2003JB002656.

Zheng X J. 2009. Mechanics of Wind-blown Sand Movements. Berlin: Springer.

Zingg A W. 1953. Wind tunnel studies of the movement of sedimentary material. In: Proceedings of the $5^{\text {th }}$ Hydraulics Conference. Bulletin. Iowa City: Institute of Hydraulics, 111-135.

Zobeck T M, Sterk G, Funk R, et al. 2003. Measurement and data analysis methods for field-scale wind erosion studies and model validation. Earth Surface Processes and Landforms, 28(11): 1163-1188. 